Exercises in the traditional style

\section{John Ziman}

Teleology Revisited. By Ernest Nagel. Pp. 352. (Columbia University Press: New York and Guildford, UK, 1979.) \$25.

THE official theology of science - as it might be enacted for example by the Council of the Royal Society if they were so wrongheaded as to ignore their own statutes forbidding such exercises - is empirical rationalism. For several centuries philosophers have been trying to elucidate and validate this creed. Of course, like any successful cultural movement, science really justifies itself by its works. But there is a species of intellectual who is not satisfied with the appearances of power, and tries to draw back the curtain hiding the machinery of science and show that it really does deserve our confidence.

In the past twenty years or so, these philosophers at the court of science have suffered a rude shock: all that they could find behind the fearful mask of the Wonderful Wizard was a little old man, gentle and wise but with no hot line to the Absolute. Critics such as Karl Popper, Norwood Russell Hanson and Thomas Kuhn have effectively demolished the claims of the scientific method as a means of arriving at certain truth.

For the older generation, this movement of Reformation has been an unhappy experience. Should they trendily embrace the latest doctrines, or should they stick with familiar beliefs that they cannot honestly discard? Professor Nagel retains "the outlook of an unreconstructed empirical rationalist", which he defends with characteristic wisdom and tolerant precision of thought and expression in this collection of essays. Although these were published independently over a period of more than 40 years, and are not artfully melded into a continuous narrative, they are remarkably consistent and coherent in style and content. If their outlook would be stigmatised as old-fashioned by the Younger Turks, it is not reactionary, and is very far from outmoded as a practical faith for the working scientist.

In fact, there are truths here that must be reckoned with. In the earlier chapters he brings to a halt the sloppier elements in Popper's fallibilist attacks on the traditional position. It may not be possible to define a general distinction between theory statements and observation statements, so that all science is in principle conjecture. But that does not mean that scientists are talking nonsense when they make such distinctions in the course of their research. Nagel acknowledges Popper's contributions in. other respects, but repulses what he aptly calls the "Mephistophelian view of science... according to which to suppose even for a moment that any problem is really solved is to lose one's soul'. And he annihilates Paul Feyerabend's irregulars after their wildly undisciplined charge to the cry "anything goes".

On the other flank, he repudiates false allies. The critique of Carnap's attempt to construct a logic of inductive reasoning is polite and detailed - but devastating. The mathematical theory of statistical inference has, I think, made some technical progress in recent years, but no intellectual structure can be safely founded on a symbol that is supposed to stand for the number of primitive predicates that might hypothetically be postulated concerning some body of evidence. To put it more succinctly than Nagel, it all seems to be a question of knowing how many beans make five. Empirical facts do not support theories by any device of strict logic.

Nevertheless, within these limits, his position is very open to attack from quite another quarter. That is to say, his genuine concern for the realities of the research process is applied solely to the arguments by which scientific knowledge is justified in the public literature. He admits that "assured knowledge in science is the product of a community of thinkers, each of whom is required by the tacit traditions of his group to be unsparing in his criticisms and evaluations of the cognitive claims presented to him"' (page 13). But he does not seem to realise the corollary that the scientific community may be (usually quite reasonably) persuaded to accept a cognitive claim on evidence that is much less watertight logically than philosophers would like. Nagel quite ignores the element of what Michael Polanyi called "tacit knowledge" in the assessment of research, and makes no reference to the social relations of the scientific community where this non-logical expertise is valued and shared.

In this light, the earliest essays in this book (dating from the 1930s) are of peculiar interest and significance. They show in detail, through the history of algebra and geometry, the pressure that can be exerted on an empirical science by the demand for logical consistency and completeness, The paradoxical appearance of imaginary numbers and imaginary points gradually drove nineteenth-century mathematicians into the modern stance, where each branch of pure mathematics is regarded simply as a system of relations derived conventionally from a prescribed set of axioms, without reference to any particular reality. In every stage of this process, extra power is gained by the increased generality of the results; but the outcome can only be correctly stated in Bertrand Russell's dictum that the pure inathematician does not know what he is talking about nor whether what he says is true.

Empirical rationalists have always been strong supporters of mathematical theory in science. They are very conscious of the value of reliably rigorous logical passages in scientific statements. But the more we purify a mathematical formalism, the more we come to realise that it is only the medium of communication between scientists and does not of itself constitute a message about the natural world. The empirical element in a scientific statement can only be expressed intelligibly in natural language, whose categories are inevitably somewhat vague. It is a pity that Nagel's remarks on this point were written before Stephan Korner had demonstrated its deadly significance for any strong logic of scientific justification.

What is also missing is a realisation of the dependence of scientific communication on non-logical human capabilities such as pattern recognition. It is true that a geometrical theorem can only be proved generally by the juxtaposition of abstract symbols for logical relations: but for most practical purposes the old Euclidean method, with its reference to diagrams, is suffiently convincing. From experimental high energy physics to sociobiology, every branch of the natural sciences is knit together by communications conveying diagrammatic inferences that cannot be interpreted by any known logical formalism but which are perfectly intelligible to another human being.

In the real world, it is the consensus that can eventually be reached by systematic intersubjective communications that defines our standards of objectivity and rationality. This applies at every level, from the everyday world of tables and chairs to the hidden world of quarks and neutrinos. It also applies to metascientific discourse on such questions as the relationship between theory and observation, or between cause and function. The point is that words like these are thematic rather than categorical. Like a picture, or a diagram, or a familiar model, they can convey very important ideas which cannot be defined, or paraphrased briefly, or precisely, or entirely unambiguously. They can only be understood in the light of experience, not of formal logic. In the final essay, Professor Nagel struggles to define the concept of teleological explication in biology, and effectively admits at the end that it was an impossible task.

Nevertheless, such strenuous exercises in the traditional style remain highly instructive for the research scientist, who must surely continue to believe, along with Professor Nagel, that "the logical methods of the modern natural sciences are the most effective instruments men have yet devised for acquiring reliable knowledge of the world and for distinguishing warranted 
claims to such knowledge from those that are not". This (as the Council of the Royal Society would correctly perceive) is the faith upon which science is built, and the disciplinary code, at platoon, regimental, and divisional level, which binds it together in its war on ignorance and error. And yet

there are perhaps occasions when such simple loyalties fail us, and the direction of the Army itself has to be called into question.

John Ziman is Professor of Physics at the University of Bristol, $U K$.

\section{Updated science policy \\ almanac}

\section{Austen Albu}

Science and Government Report International Almanac, 1978-1979. Edited by D.S. Greenberg and A.D. Norman. Pp. 368. (Science and Government Report, Inc., P.O. Box 6226, 3736 Kanawha St NW, Washington DC, 20015, 1979.) \$54.

IT can be assumed that any study published today on government policy and organisation for science will be more concerned with technology than with pure science. Whether in captialist or communist countries this represents a victory for those pre-War marxist scient ists who advocated planned support for science applied to utilitarian ends. The new edition of this valuable report, covering a period when economic difficulties restrained the expediture of most countries on R\&D, makes it clear that pure science plays a decreasing role in government support policies compared with applied science and technology. Even Israel, which claims high support for basic research, based on its traditional approach to learning, has seen a significant increase in the proportion of applied research and development in the past few years. Although they do not all follow the same pattern, these national reports give an invaluable picture of recent developments in public policy and attitudes, and in changes in organisation for scientific advice and the carrying out of policy.

All governments support $R \& D$, but the degree to which they do so financially and the organisations they use for the purpose vary a good deal. Britain and France seem to be among those countries with the most centralised structures among the advanced industrial nations. Even the USSR, if one forgets the overarching position of the Party, seems to have a wider range of institutions, although they are constantly changing. The growing emphasis on R\&D to improve industrial production seems to have led to some decline in the prestige of the Academy of Sciences in face of the State Committee for Science and Technology.
In the United States the growth of anxiety in official circles about the country's apparent diminishing capacity for industrial innovation was one reason for President Carter's proposals to raise the rate of growth of funds for $R \& D$, especially basic research. Congress, however, had rather different ideas and kept the 1979 expenditure to a total only fractionally more than that of 1978 . One of the results of the increased involvement of governments in science and technology is the politicising of the decision-making process. In that most democratic of federations, Switzerland, the voters in referenda have displayed hostility to expansion of the universities and to subsidies to industry for R\&D. This may be of little importance as Switzerland has the highest per capita rate of $R \& D$ expenditure in the world; $80 \%$ of it by private industry. Apart from wishing to curtail government expenditure, some voters in most countries are becoming increasingly interested in 'ethical' aspects of science or questions of the effects of technology on 'life style'. The main targets at present are nuclear energy and recombinant DNA. The former is an obvious embarassment for governments struggling with energy problems and no doubt adds to the growing part energy plays in national research programmes. Popular interest in the supposed dangers of recombinant DNA has been greatest in the USA and UK; in most other countries it has only attracted the attention of scientists and administrators.

The richer countries are concerned with problems of health research, both its changing nature and its accelerating cost. In the USA the Secretary of the Department of Health, Education and Welfare addressed scientists last year on the need to devise "health research principles" to be used for planning a "rolling" five year budget for the Department's programmes. The Federal Republic of Germany has published a programme of Promoting Research in the Service of Health, 1978-1981, of which an extremely interesting excerpt from the English translation is reproduced. It includes an examination of the difficulties of health research and a detailed list of fields in which greater R\&D efforts would seem to be necessary.

So far the Trades Union in most countries have not shown much sustained interest in the problems involved in the results of scientific research. Only in the Scandinavian countries have permanent bodies been established by the Unions to keep them under survey. In France the scientific associations acted as pressure groups during the Presidential election of 1979 in which science policy played a prominent part.

Some rather unexpected figures in the output of scientist are revealed. In Sweden there was a fall in the output of Doctorates in the Natural Sciences between 1970 and 1976 from 461 to 172 . In Britain, during the period of university growth in the $1960 \mathrm{~s}$ scientific subjects got left behind, so that the "swing away from science" in the 1970 's seems by contrast fairly modest On the other hand engineering, at least in numbers, kept pace with university expansion. This, however, does not take account of a rapidly growing number of foreign students. The most unbalanced figures come from India which, in 1977, produced 140,600 graduates in the Natural Sciences and 15,000 in Engineering; bringing the total number of science graduates in the population to $1,182,272$ of whom $16.1 \%$ were unemployed and of engineers to 251,860 of whom $2.4 \%$ were unemployed.

The most significant differences between nations lie in the ratio of government to private industry financed $R \& D$ and the proportion of military expediture. This may provide at least a partial explanation for the decline of British industrial performance. In Britain, France and the USA goverment provides more than half the nation's R\&D funds; in Germany, Italy, the Netherlands, Sweden and Canada between $\mathbf{4 0}$ and $50 \%$. In Japan the figure is about $30 \%$, but Japan has the third largest R\&D programme in the world. What is more significant is the fact that in the UK annd the USA roughly $50 \%$ of government R\&D funds are spent on military programmes against a EEC average of $23 \%$, a German figure of 12 and Japanese of 2. In all the major Western countries except the UK the share of government R\&D spent on military programmes declined during the 1970 s. In the UK it increased between 1970 and 1976 from 41 to $48 \%$. If research expenditure is to be reduced these figures indicate where the possiblities of cuts should at least be scrutinised. On the other hand it seems that R\&D activity by industry has been declining in the UK while that of the UK's main competitors has been rising; a matter which must be of concern to a government committed to reversing the decline of British industrial competitiveness.

This is the second year of publication of this important almanac. As an essential source of reference for scientific administrators, politicians and students of the subject it is to be hoped that it has now become firmly established in the rather overgrown forest of journals dealing with science policy.

Austen Albu is a Visiting Research Fellow of the Science Policy Research Unit, University of Sussex, Brighton, UK. 